University of Windsor

Scholarship at UWindsor

2009

\title{
A membrane basis for bacterial identification and discrimination using laser-induced breakdown spectroscopy
}

Steven J. Rehse

University of Windsor

N. Jeyasingham

J. Diedrich

S. Palchaudhuri

Follow this and additional works at: https://scholar.uwindsor.ca/physicspub

\section{Recommended Citation}

Rehse, Steven J.; Jeyasingham, N.; Diedrich, J.; and Palchaudhuri, S.. (2009). A membrane basis for bacterial identification and discrimination using laser-induced breakdown spectroscopy. Journal of Applied Physics, 105 (10).

https://scholar.uwindsor.ca/physicspub/14

This Article is brought to you for free and open access by the Department of Physics at Scholarship at UWindsor. It has been accepted for inclusion in Physics Publications by an authorized administrator of Scholarship at UWindsor. For more information, please contact scholarship@uwindsor.ca. 


\section{AIP Appilied Physics}

\section{A membrane basis for bacterial identification and discrimination using laser-induced breakdown spectroscopy}

Steven J. Rehse, Narmatha Jeyasingham, Jonathan Diedrich, and Sunil Palchaudhuri

Citation: J. Appl. Phys. 105, 102034 (2009); doi: 10.1063/1.3116141

View online: http://dx.doi.org/10.1063/1.3116141

View Table of Contents: http://jap.aip.org/resource/1/JAPIAU/v105/i10

Published by the American Institute of Physics.

\section{Additional information on J. Appl. Phys.}

Journal Homepage: http://jap.aip.org/

Journal Information: http://jap.aip.org/about/about_the_journal

Top downloads: http://jap.aip.org/features/most_downloaded

Information for Authors: http://jap.aip.org/authors

\section{ADVERTISEMENT}

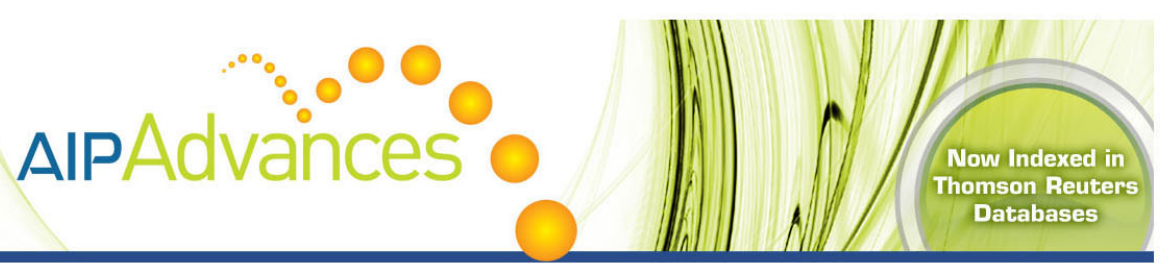

\section{Explore AIP's open access journal: Rapid publication \\ - Article-level metrics \\ - Post-publication rating and commenting}




\title{
A membrane basis for bacterial identification and discrimination using laser-induced breakdown spectroscopy
}

\author{
Steven J. Rehse, ${ }^{1, a)}$ Narmatha Jeyasingham, ${ }^{1}$ Jonathan Diedrich, ${ }^{1}$ and \\ Sunil Palchaudhuri ${ }^{2}$ \\ ${ }^{1}$ Department of Physics and Astronomy, Wayne State University, Detroit, Michigan 48201, USA \\ ${ }^{2}$ Department of Immunology and Microbiology, Wayne State University, Detroit, Michigan 48201, USA
}

(Received 29 March 2008; accepted 5 June 2008; published online 19 May 2009)

\begin{abstract}
Nanosecond single-pulse laser-induced breakdown spectroscopy (LIBS) has been used to discriminate between two different genera of Gram-negative bacteria and between several strains of the Escherichia coli bacterium based on the relative concentration of trace inorganic elements in the bacteria. Of particular importance in all such studies to date has been the role of divalent cations, specifically $\mathrm{Ca}^{2+}$ and $\mathrm{Mg}^{2+}$, which are present in the membranes of Gram-negative bacteria and act to aggregate the highly polar lipopolysaccharide molecules. We have demonstrated that the source of emission from $\mathrm{Ca}$ and $\mathrm{Mg}$ atoms observed in LIBS plasmas from bacteria is at least partially located at the outer membrane by intentionally altering membrane biochemistry and correlating these changes with the observed changes in the LIBS spectra. The definitive assignment of some fraction of the LIBS emission to the outer membrane composition establishes a potential serological, or surface-antigen, basis for the laser-based identification. E. coli and Pseudomonas aeruginosa were cultured in three nutrient media: trypticase soy agar as a control, a MacConkey agar with a $0.01 \%$ concentration of bile salts including sodium deoxycholate, and a trypticase soy agar with a $0.4 \%$ deoxycholate concentration. The higher concentration of deoxycholate is known to disrupt bacterial outer membrane integrity and was expected to induce changes in the observed LIBS spectra. Altered LIBS emission was observed for bacteria cultured in this $0.4 \%$ medium and laser ablated in an all-argon environment. These spectra evidenced a reduced calcium emission and in the case of one species, a reduced magnesium emission. Culturing on the lower $(0.01 \%)$ concentration of bile salts altered the LIBS spectra for both the P. aeruginosa and two strains of E. coli in a highly reproducible way, although not nearly as significantly as culturing in the higher concentration of deoxycholate did. This was possibly due to the accumulation of divalent cations around the bacteria by the formation of an extracellular polysaccharide capsule. Lastly, a discriminant function analysis demonstrated that in spite of alterations in the LIBS spectrum induced by growth in the three different media, the analysis could correctly identify all samples better than $90 \%$ of the time. This encouraging result illustrates the potential utility of LIBS as a rapid bacteriological identification technology. (0) 2009 American Institute of Physics. [DOI: 10.1063/1.3116141]
\end{abstract}

\section{INTRODUCTION}

\section{A. Laser-induced breakdown spectroscopy on biological samples}

Laser-induced breakdown spectroscopy (LIBS) is an alloptical analytical technique that utilizes a pulsed laser and optical spectroscopy to detect and identify the constituent elements present in a target material by creating a hightemperature microplasma within the focal region of the laser. The experimental procedures utilized in this technique and the physics used to model and describe the breakdown process and the resulting plasmas have been discussed previously in great detail (see, for example, the books by Cremers and Radziemski ${ }^{1}$ and Miziolek et $a .^{2}$ or review articles by Tognoni et $a l_{.}^{3}$ and Pasquini et $a l .{ }^{4}$ ). While the LIBS technique has been utilized extensively over the past 20 years in a wide variety of spectroscopic and industrial applications, ${ }^{5}$ only since 2003 has LIBS been used to identify and discrimi-

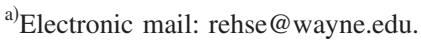

nate a wide variety of microorganisms such as bacteria, fungal/mold spores, pollens, and proteins based on the emission intensity of trace inorganic elements contained in the microorganism. ${ }^{6-15}$ The success of these early experiments was a result of the positive identification of many elemental lines within the emission spectrum from these biological targets which provided an immediate and unique spectral "fingerprint" which could be used to positively identify the microorganism in the sample.

The ability to rapidly (within seconds or minutes) detect harmful pathogens using LIBS—including those pathogens that cannot be cultured within a reasonable amount of time or cannot be cultured at all—offers an alternative paradigm to the health sciences for the detection, identification, and control of infectious diseases. While the current methods of identifying bacteria can yield accurate results, they also require removal of the sample to a laboratory setting, direct contact (handling) of the potentially pathogenic sample, and above all are often too slow to provide results which could direct responses or treatments which may be time sensitive. 
It is also known that the microbiological expertise and cost required to perform these identifications preclude their common use as a screening mechanism to prevent human infection. ${ }^{16}$ This lack of convenient testing has led to everincreasing rates of food-borne outbreaks and secondary infections in hospitals. ${ }^{17}$

Our recent work has focused on two Gram-negative bacteria of concern to the fields of clinical sciences and public health: Escherichia coli ${ }^{18,19}$ and Pseudomonas aeruginosa. ${ }^{20}$ In particular, we have demonstrated the ability to discriminate several nonpathogenic strains of $E$. coli from each other and from the pathogenic strain of enterohemorrhagic $E$. coli (EHEC) O157:H7, which causes kidney failure and deaths in children. $^{21} \mathrm{~A}$ series of recent results by Baudelet and coworkers showed with great success the utility of using both nanosecond and femtosecond LIBS to identify the E. coli bacterium. ${ }^{22-24}$ Also, E. coli has been completely characterized genetically, has many nonpathogenic strains, and is easy to grow, ${ }^{25}$ making it an ideal test bacterium for LIBS studies. All the experiments described in this paper were conducted on three strains of E. coli: an environmental strain, E. coli C (Nino) which we will refer to hereafter as Nino C; a derivative of the laboratory K-12 strain, HF4714; and the pathogenic E. coli, EHEC.

Pseudomonas aeruginosa is an opportunistic pathogen ubiquitous in hospital environments which complicates patient treatments due to increasing rates of nosocomial infections. While $E$. coli is very much so an intestinal bacteria, $P$. aeruginosa is not. $P$. aeruginosa is best known for its ability to infect burns and to cause complications in patients with cystic fibrosis (CF). CF patients typically develop persistent $P$. aeruginosa lung infections that lead to lung failure, followed by transplants or early death. The treatment of $P$. aeruginosa infections is complicated by its propensity to develop antibiotic resistance. ${ }^{26}$ LIBS experiments were performed on both $E$. coli and $P$. aeruginosa as a demonstration of the technique's efficacy at discriminating between these two very common yet medically important pathogens.

While the proof of concept use of LIBS to discriminate bacterial targets in idealized laboratory situations has been demonstrated, one of the most significant issues that must be addressed is the inherent biochemical adaptability of the bacteria to their environment. Specifically, it must be proven that the ability to identify a given target organism is not eliminated by the bacteria's exposure to a wide variety of growth conditions and/or nutrient environments. Early work by Leone $e t a l .{ }^{27}$ concluded that discrimination of two strains of Bacillus globigii cultured in two different kinds of nutritive media was indeed possible. We have also demonstrated that $P$. aeruginosa cultured in a trypticase soy agar (TSA) medium (a surrogate for a sputum sample) and on a blood agar plate (BAP) (a surrogate for a blood sample) showed no substantial difference in our discrimination. ${ }^{20}$ However, we also demonstrated that when the bacterial membrane was purposefully altered via culturing in a nutrient medium containing bile salts or its deoxycholate component, a substantial alteration of the optical LIBS emission was observed. This last experiment was particularly relevant for clinical diagnoses because food-borne and water-borne pathogens are ex- posed to similar bile salts in the digestive system immediately after ingestion.

The purpose of this article is twofold: to further investigate the extent to which the identification and discrimination of Gram-negative bacteria is disrupted by the intentional alteration of membrane biochemistry due to growth in known environments and to begin to establish a biochemical connection between the current serological (or surface-antigen) basis for bacterial identification and the LIBS identification described herein.

\section{B. Gram-negative bacteria physiology and its relation to LIBS identification/serological classification}

In general, bacteria can be divided into two major groups, called Gram-positive and Gram-negative. The original distinction between Gram-positive and Gram-negative was based on a special staining procedure, the Gram stain, but differences in cell wall structure are at the base of these differences in the Gram staining reaction. ${ }^{28}$ Gram-negative bacteria surround themselves with a double membrane and a thin cell wall of peptidoglycans. Gram-positive bacteria possess a cytoplasmic membrane overlaid by a thick cell wall of peptidoglycans. ${ }^{29}$ This cytoplasmic membrane is common to both bacteria. By altering membrane biochemistry and observing changes in the observed LIBS spectra, we can prove that inorganic composition of the membrane is at least partially responsible for LIBS-based bacterial identification.

The outer membrane of the Gram-negative bacteria is first and foremost a permeability barrier, but primarily due to its polysaccharide content, it possesses many of the interesting and important characteristics of Gram-negative bacteria. ${ }^{29,30}$ The inner face of the outer membrane is composed of phospholipids, while the outer face is mainly formed by a different type of amphilic molecule, which is composed of lipopolysaccharide (LPS). ${ }^{31,32}$ The LPS molecule is composed of an inner hydrophobic region, called lipid A, which is attached to a hydrophilic linear polysaccharide region, consisting of the core polysaccharide and the O-specific polysaccharide. ${ }^{33}$ The LPS molecule is shown schematically in Fig. 1.

Variations in LPS composition even within a species allow it to be used to identify the bacterium in what is known as a "serological classification." Based on the reactivity of the outer membrane to introduced antigens, bacteria have been classified for a long time on the basis of their LPS O-antigen which has been a crucial step for diagnostic and epidemiological identification. This serological classification is very frequently used today in clinical laboratories and hospitals and is more commonly used for bacterial identification than the variety of molecular biology techniques that have recently arisen (oligonucleotide microarrays, 16S rRNA probes, polymerase chain reaction (PCR), etc.). ${ }^{34-36}$ However because of antigenic variation, which can be induced by bacteriophage infection or by transposable DNA elements, ${ }^{37,38}$ such classification needs independent confirmation by the development of a diagnostic technology at a molecular or atomic level.

It is known that at least two specific divalent cations, $\mathrm{Ca}^{2+}$ and $\mathrm{Mg}^{2+}$, play a crucial role in stabilizing the mem- 


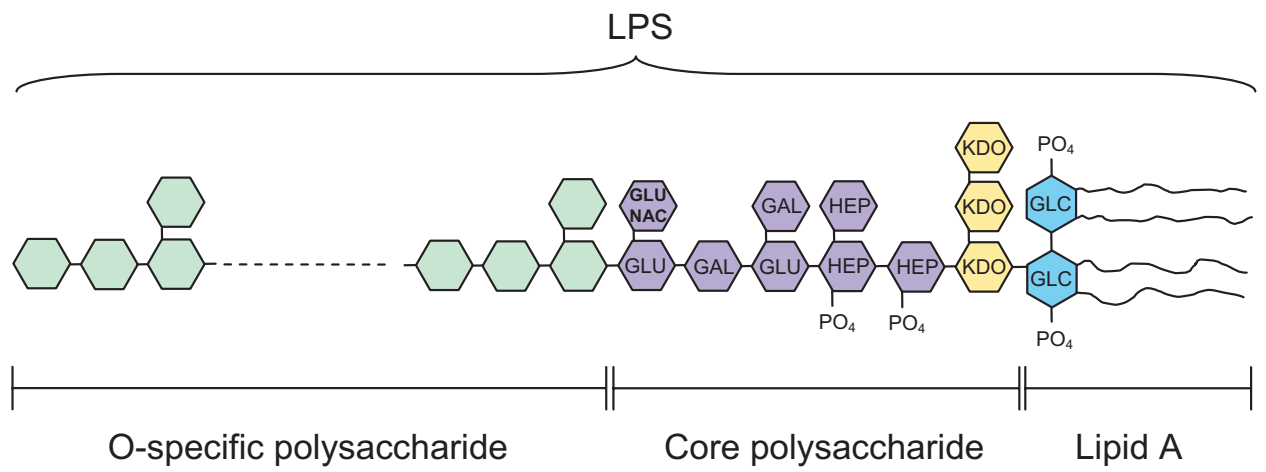

FIG. 1. (Color) A schematic structure of the LPS molecule that comprises the outer sheath of the Gram-negative lipid bilayer outer membrane. Three distinct regions exist. The inner lipid A region anchors the molecule into the hydrophobic domain of the bilayer. The middle core polysaccharide region possesses an overall electronegative charge and the majority of divalent $\mathrm{Mg}^{2+}$ and $\mathrm{Ca}^{2+}$ binding sites exist in the KDO region. The outer face of the molecule is the $\mathrm{O}$-antigen or $\mathrm{O}$-side chain region which consists of repeating tetrasaccharides which are hydrophilic: GLC, glucosamine; $\mathrm{PO}_{4}$, phosphate; $\mathrm{KDO}$, keto- $d$-octulosonic acid; HEP, heptose; GLU, glucose; GAL, galactose; and GLUNAC, $N$-acetyl glucosamine.

brane by binding the electronegative LPS molecules. ${ }^{39}$ It has been found that these cations can dramatically change immunological and biophysical parameters (such as acyl chain order and aggregate packing structure) which can have profound effects on LPS physiology and bacteria bioactivity, ${ }_{40,41}$ although the exact mechanisms of this are not known. ${ }^{42-45}$ Changes in the cation concentration may in some way be linked to epitopes of the bacteria, which are antigen binding sites required for serological identification of the bacteria and it is these metallic cations to which LIBS is particularly sensitive. This is suggestive that the LIBS identification is in some way related to the serological classification of the organism.

\section{EXPERIMENTAL SETUP}

\section{A. Microbiological sample preparation}

Three strains of $E$. coli and one strain of $P$. aeruginosa were cultured in a variety of nutrient media, each chosen to induce a specific reaction within the membrane of these Gram-negative bacteria for $24 \mathrm{~h}$ at $37^{\circ} \mathrm{C}$. Such growth conditions yielded a single colony of roughly $(1-5) \times 10^{6}$ bacteria. One of the substrates was a TSA nutrient medium. TSA is a rich bacteriological growth medium containing pancreatic digest of casein, soybean meal, $\mathrm{NaCl}$, dextrose, and dipotassium phosphate. A second substrate was a BAP. A BAP is a TSA plus blood medium substrate, which is often used to phenologically identify hemolytic activity from the bacteria and was chosen to simulate a sample obtained diagnostically from a blood infection. The TSA substrate more effectively simulated a sample obtained environmentally or from sputum.

A third substrate was a MacConkey plus lactose (MAC) nutrient medium with bile salts (including sodium deoxycholate) at a concentration of $0.01 \%$. It is generally accepted that the hydrophobic bile salts can cause a disruption of the membrane integrity after solubilization of the membrane lipids and that one of the functions of the outer membrane is to prevent the detergent action of such bile salts. ${ }^{30,46}$ These salts are also related to the virulence of certain organisms ${ }^{47}$ and have also been shown to make the bacteria more resistant to lipophilic antibiotics. ${ }^{48}$ At the low concentrations of bile salts used in this initial experiment, membrane disruption is not yet expected. Instead, bacteria such as $P$. aeruginosa may form a biofilm during growth in this medium. ${ }^{49}$ In Gramnegative bacteria, a biofilm is an excessive production of exopolysaccharide which forms a mucoid capsule. This biofilm helps to protect the pathogen against the inflammatory defense mechanism of a host. ${ }^{50,26}$ It is possible that bacteria grown in the presence of a low concentration of bile may accumulate the divalent cations is such a polysaccharide capsule which could consequently affect the identification by LIBS. In contrast, in the presence of $0.2 \%$ or higher concentration of bile salts (or deoxycholate), it has been shown that the LPS is displaced and dispersed, reducing the exopolysaccharide formation. ${ }^{51}$ To test this, samples were grown in a TSA medium containing $0.4 \%$ sodium deoxycholate. Cultures grown in this medium were noticeably smaller due to the inhibitory effect of the deoxycholate and possessed different tactile properties than the other samples. The purity of the cultures of all bacterial strains used in this study was routinely confirmed by streaking on L-agar plates, MAClactose plates, and by bacteriophage sensitivity assays.

\section{B. LIBS apparatus}

After culturing, the bacteria were transferred to the surface of a $0.7 \%$ agar plate with a very thin smear. The choice of agar as an ablation substrate provided a flat, large area substrate with a high-breakdown threshold. The specific advantage of utilizing this highly watery agar was that it did not contribute directly or indirectly to the LIBS spectra of the bacteria. The optical emission from this agar was an order of magnitude smaller than that from the bacteria and lacked many of the elements present in the bacteria. Therefore it did not contribute significantly to a background signal.

Our LIBS apparatus has been described in detail elsewhere. ${ }^{19} 10 \mathrm{~ns}$ laser pulses from an Nd:YAG (yttrium aluminum garnet) laser (Spectra Physics, LAB-150-10) operating at its fundamental wavelength were focused by a microscope objective to ablate the bacteria and the optical emission from the LIBS microplasma was dispersed in an Échelle spectrometer equipped with a $1024 \times 1024$ (24 


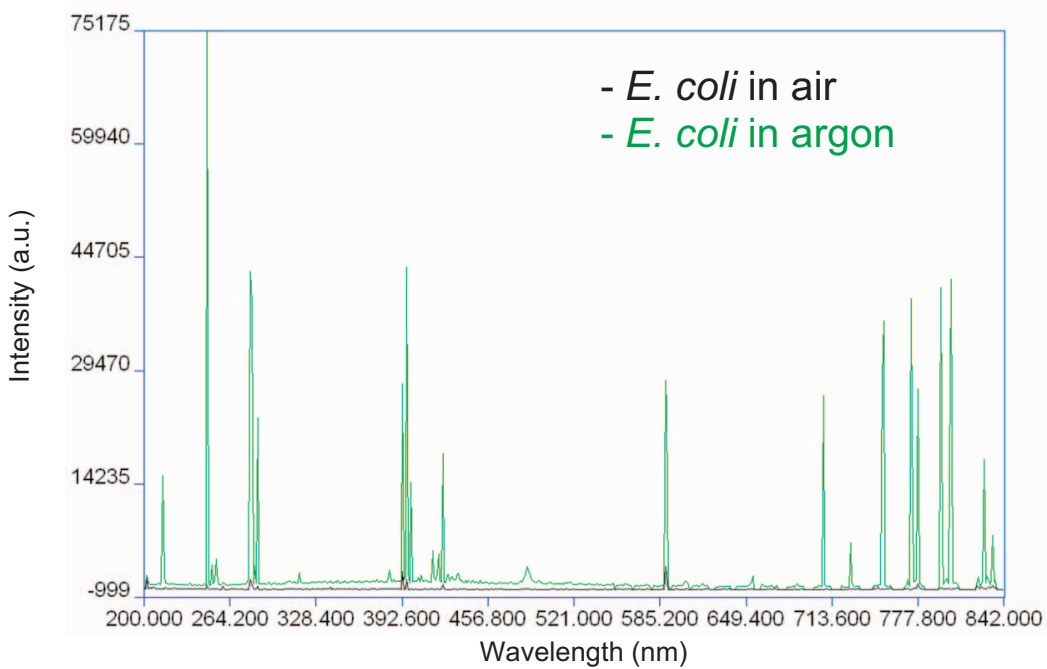

FIG. 2. (Color) E. coli laser ablated in air (black, lower spectrum) and argon (green, upper spectrum). Experimental parameters were similar (except for delay time). Spectra acquired in argon exhibited significantly larger atomic emission as well as an enhanced background.

$\times 24 \mu \mathrm{m}^{2}$ pixel area) intensified charge coupled device (ICCD)-array (LLA Instruments, Inc., ESA3000) which provided complete spectra coverage from 200 to $840 \mathrm{~nm}$ with a resolution of $0.005 \mathrm{~nm}$ in the UV. The laser spot size was approximately $100 \mu \mathrm{m}$ in the objective's focal plane, and the typical pulse energies at the ablation surface were $8 \mathrm{~mJ} /$ pulse.

LIBS spectra were acquired at a delay time of $1 \mu$ s after the ablation pulse, with an ICCD intensifier gate width of $20 \mu$ s duration. This delay time was chosen to maximize emission from the strongest, most obvious emission lines while minimizing the contribution from the broadband background emission. Spectra from ten laser pulses were accumulated on the CCD chip prior to readout. The sample was then manually translated $250 \mu \mathrm{m}$ and another set of ten laser pulses was averaged. Five accumulations were averaged in this way, resulting in a spectrum comprised of 100 laser pulses that took approximately $40 \mathrm{~s}$ to obtain. Typically 20-30 such measurements could be made from one colony $24 \mathrm{~h}$ after initial streaking.

Initial experiments on $P$. aeruginaosa were conducted in an air atmosphere. However the vast majority of experiments were conducted in an argon environment at atmospheric pressure. The enhancement in optical emission due to the Ar environment is well known and has been detailed in previous works. ${ }^{52-54}$ A comparison of a LIBS spectrum from bacteria ablated in air and in argon is shown in Fig. 2. Both spectra are of $E$. coli obtained with similar parameters. However the use of argon necessitated a change in the delay time to $4 \mu \mathrm{s}$. The use of these longer delay times avoided potential complications from the broadband background (which is still enhanced relative to the air spectrum as can be seen in Fig. 2) inherently observed with such substrates. The increase in optical emission allowed us to reduce the number of laser pulses fired per location to 5 and lower the number of accumulations to 5. This was advantageous as the number of bacteria cultured on deoxycholate was smaller, as mentioned earlier. Also, we were able to see and utilize more atomic lines for identification. Phosphorus in particular, was significantly more visible in the argon plasmas than in air. We increased the number of spectral lines used in the analysis from 19 (detailed in Ref. 20) to 31. All 31 lines are listed in Table I.

The integrated area under these emission lines was obtained via nonlinear least squares fitting and the resulting 31

TABLE I. Resolved spectral emission lines observed in LIBS spectra acquired from Escherichia coli (strain Nino C) in an argon environment. The atomic and ionic lines are identified and categorized by whether emission from them was consistently strong $(+)$, average sized $(\bigcirc)$, or weak $(-)$. Weak lines were frequently unobserved in less intense plasmas.

\begin{tabular}{|c|c|c|}
\hline $\begin{array}{l}\text { Wavelength } \\
\qquad(\mathrm{nm})\end{array}$ & $\begin{array}{c}\text { Line } \\
\text { identification }\end{array}$ & Strength \\
\hline 203.347 & P I & - \\
\hline 213.546 & P I & o \\
\hline 213.618 & P I & + \\
\hline 214.914 & P I & + \\
\hline 215.294 & P I & - \\
\hline 215.408 & P I & - \\
\hline 247.856 & C I & + \\
\hline 253.398 & P I & o \\
\hline 253.560 & P I & + \\
\hline 255.326 & P I & + \\
\hline 255.491 & P I & o \\
\hline 277.983 & Mg I & + \\
\hline 279.079 & Mg II & + \\
\hline 279.553 & Mg II & + \\
\hline 279.806 & Mg II & + \\
\hline 280.271 & Mg II & + \\
\hline 285.213 & $\mathrm{Mg} \mathrm{I}$ & + \\
\hline 315.887 & $\mathrm{Ca}$ II & o \\
\hline 317.933 & Ca II & + \\
\hline 373.690 & Ca II & - \\
\hline 382.931 & Mg I & - \\
\hline 383.231 & $\mathrm{Mg} \mathrm{I}$ & o \\
\hline 383.829 & $\mathrm{Mg} \mathrm{I}$ & o \\
\hline 393.366 & $\mathrm{Ca}$ II & + \\
\hline 396.847 & Ca II & + \\
\hline 422.673 & Ca II & + \\
\hline 430.253 & $\mathrm{Ca} \mathrm{I}$ & - \\
\hline 518.361 & Mg I & o \\
\hline 588.995 & $\mathrm{Na} \mathrm{I}$ & + \\
\hline 589.593 & $\mathrm{Na} \mathrm{I}$ & + \\
\hline 769.896 & K I & - \\
\hline
\end{tabular}




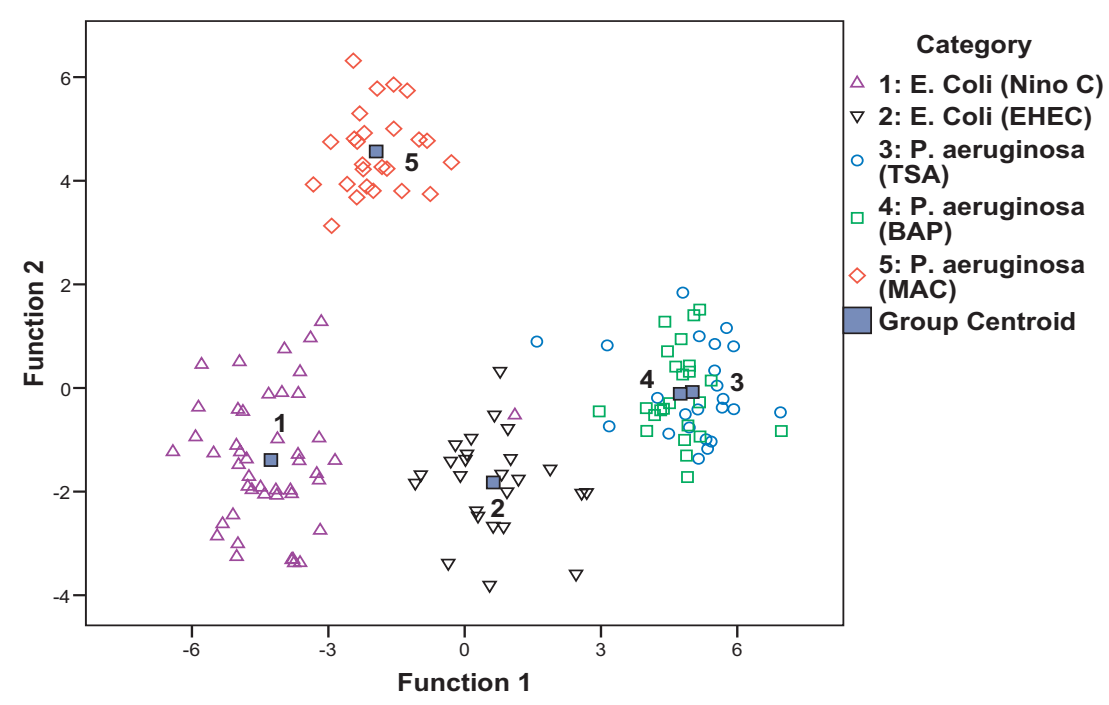

FIG. 3. (Color) DFA scores for two strains of $E$. coli (Nino C and EHEC) and a single strain of $P$. deruginosa cultured in three different nutrient media: TSA, MacConkey agar containing $0.01 \%$ bile salts (MAC), and a BAP. The bacteria cultured in the MacConkey agar plus bile salts exhibited a significant difference from the other $P$. aeruginosa spectra based on calcium and magnesium concentrations. areas were utilized as independent predictor variables in a multivariate analysis called discriminant function analysis (DFA). The computerized DFA performed by the SPSS software was described previsouly. ${ }^{20}$ The result of the analysis is to reduce the dimensionality of the 31 independent predictor variables to a few scalar quantities known as discriminant function scores. For discrimination amount $N$ different groups of spectra, $N-1$ discriminant function scores were obtained per spectrum. These scores were then plotted, usually in a two dimensional graph showing each spectrum's discriminant function one (DF1) score and discriminant function two (DF2) score. Differences in DF1 scores are always more significant than differences in DF2 scores since the first discriminant function is constructed on the basis of the most significant difference among spectra. Higher order discriminant functions always account for less of the variation among spectra.

\section{EXPERIMENTAL RESULTS AND DISCUSSIONS}

\section{A. Alteration of $\boldsymbol{P}$. aeruginosa spectrum by bile salts}

The spectra from two strains of $E$. coli (Nino $\mathrm{C}$ and EHEC) ablated in air were compared to the spectra from $P$. aeruginosa cultured in TSA, a BAP, and a MacConkey MAC containing $0.01 \%$ bile salts in a DFA. The results are shown in Fig. 3. The E. coli discriminated well from the P. aeruginosa and were readily identified. The spectra from $P$. aeruginosa cultured in TSA and BAP were identical, as expected, but the spectra from bacteria cultured in MacConkey with $0.01 \%$ bile salts were significantly altered. In this analysis if the identity of any given spectrum was assumed to be unknown and the analysis was asked to identify it based on functions constructed from the other spectra (a technique known as a "leave one out" or "cross-validation" analysis), Nino C was correctly identified $97.8 \%$ of the time. In such an analysis, EHEC was correctly identified $100 \%$ of the time, $P$. aeruginosa cultured in TSA $82.6 \%$ of the time (the rest of the time identified as being grown in BAP), P. aeruginosa cultured in BAP $87.5 \%$ of the time, (the rest of the time identified as grown in TSA), and the $P$. aeruginosa cultured in the bile salt medium correctly identified $100 \%$ of the time.
The similarity in DF1 score of the Pseudomonas samples cultured in the bile salt medium and the two E. coli samples indicated that these spectra appeared to look more like $E$. coli. If these $P$. aeruginosa spectra were left unclassified altogether, and the analysis was asked to identify the spectra, $72 \%$ of the time these spectra were identified as Nino C, $24 \%$ of time as EHEC, and only $4 \%$ of the time as Pseudomonas. The presence of the bile salts changed the bacterial spectrum in such a way as to make them completely distinct, and the ability to identify them as $P$. aeruginosa disappeared. If this spectral alteration was due to the formation of a biofilm capsule, this result is suggestive that the presence of a biofilm may disrupt LIBS-based bacterial identification performed in air. It has previously been observed in non-LIBS experiments that growth of $P$. aeruginosa in a biofilm induced phenotypic variation. ${ }^{55}$

The structure matrix of this DFA showed that emission lines from calcium and magnesium were the dominant variables in constructing DF2, which clearly separated the bile salt-cultured bacteria from the others. An analysis of the total spectral power associated with the emission lines in these spectra allowed us to qualitatively describe the changes in the relative concentration of the six elements used in the analysis. This is shown in Fig. 4. The fraction of the total spectral power due to calcium emission increased, while the fraction of the total spectral power due to magnesium emission decreased. The emission from the other four elements was unchanged. We also obtained LIBS spectra from the three substrates themselves. When analyzed by DFA with the bacteria grown on them, no significant difference of any kind was observed among the three and yet the bacteria showed no similarities to the media, proving it was definitely not trace residues of nutrient medium responsible for the discrimination. This can be seen in Figs. 3 and 4 of Ref. 20 as well as in the chemical compositions shown in Fig. 4. We thus attribute the alteration of the bile salt-cultured Pseudomonas spectra to an increase in calcium and a decrease in magnesium in the LIBS plasma, and thus in the ablated sample. It is not yet possible to discern whether this is due to a biochemical change in the membrane or accumu- 


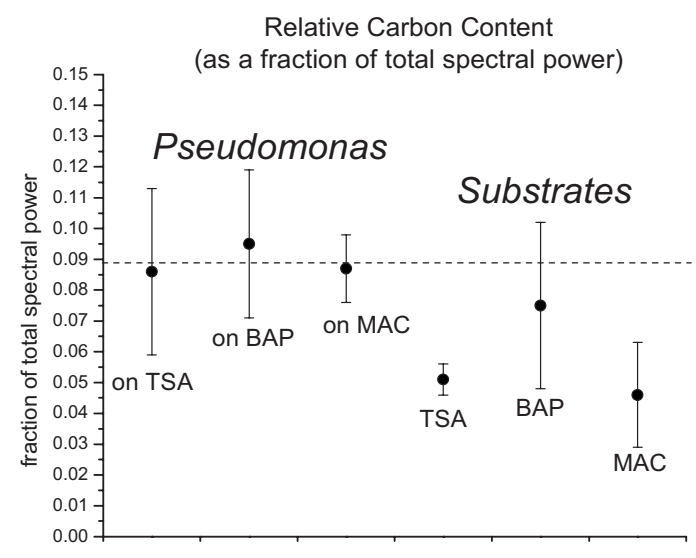

Relative Calcium Content (as a fraction of total spectral power)

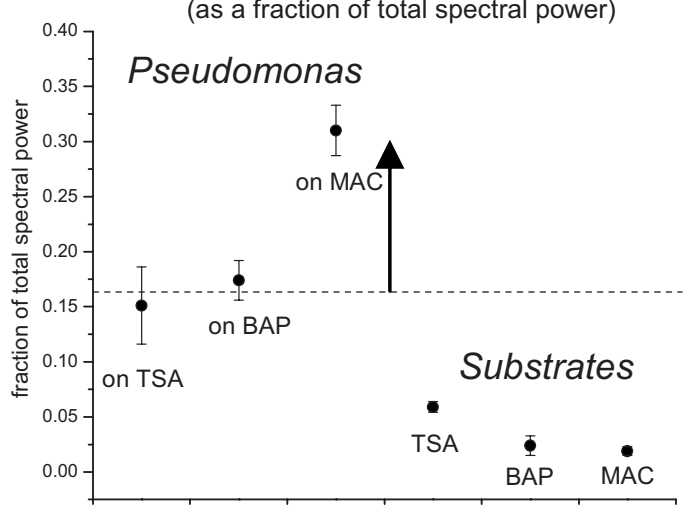

Relative Magnesium Content (as a fraction of total spectral power)

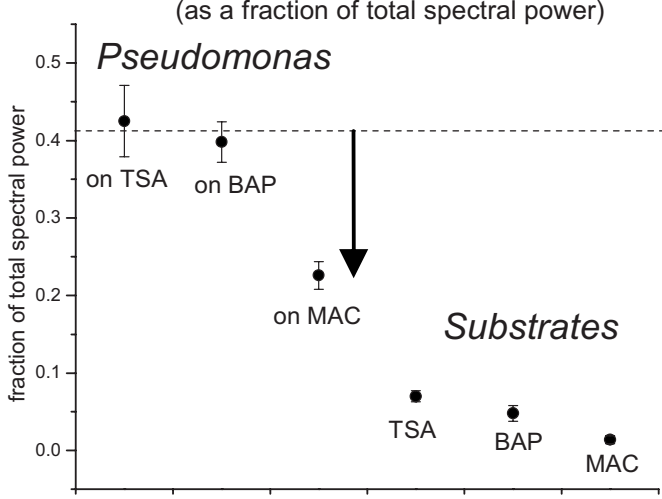

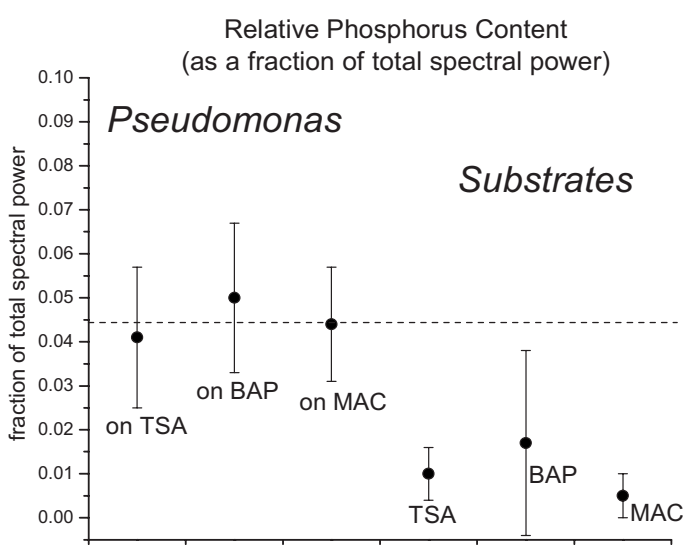

Relative Sodium Content (as a fraction of total spectral power)
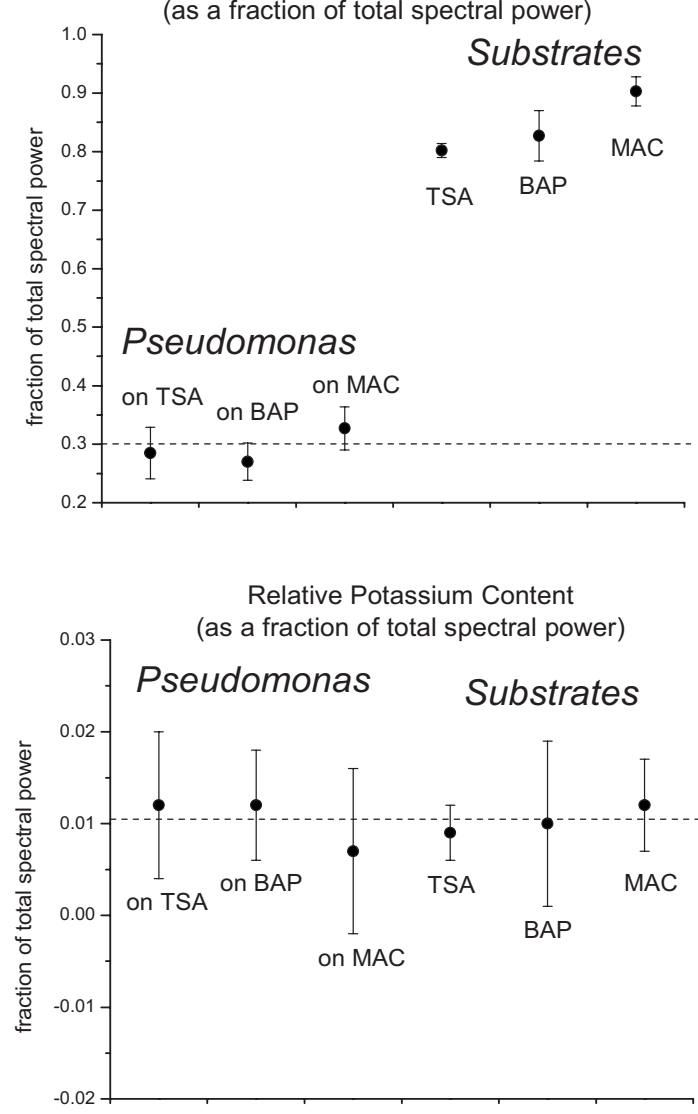

FIG. 4. The fraction of the total spectral power associated with each of the six elements observed in LIBS plasmas of P. aeruginosa ablated in air. Bacteria samples were cultured for $24 \mathrm{~h}$ in TSA, a BAP and in MacConkey agar containing $0.01 \%$ bile salts (MAC). The only elements to show any significant change as a function of nutrient medium are calcium and magnesium. Also shown are the data from the media themselves, which are particularly strong in sodium.

lation in a secreted exopolysaccharide capsule and this will be the subject of future experiments.

\section{B. Alteration of $P$. aeruginosa spectrum by $0.4 \%$ deoxycholate}

We next investigated whether $P$. aeruginosa cultured in a TSA medium with $0.4 \%$ sodium deoxycholate would yield a spectrum similar to samples cultured in TSA alone or in MacConkey agar with bile salts. While the formation of a biofilm is anticipated in the presence of low concentrations of bile salts, it is unlikely in the presence of higher concentrations of deoxycholate such as the $0.4 \%$ used in this experiment. Indeed we expected this concentration to begin to dis- perse the LPS layer due to the detergent action of the deoxycholate. Samples were cultured in the manner described earlier in TSA, MAC with $0.01 \%$ bile salts, and TSA with $0.4 \%$ deoxycholate. Cultures were transferred to the $0.7 \%$ agar medium, LIBS was preformed, and the results analyzed by a DFA. This experiment and all subsequent experiments were performed in an argon environment at atmospheric pressure. The results of this analysis are shown in Fig. 5, which shows the first two discriminant function scores for spectra from the three bacteria samples and also from the nutrient media themselves.

The spectra from bacteria cultured in the deoxycholate showed a substantial difference from the bacteria cultured in 


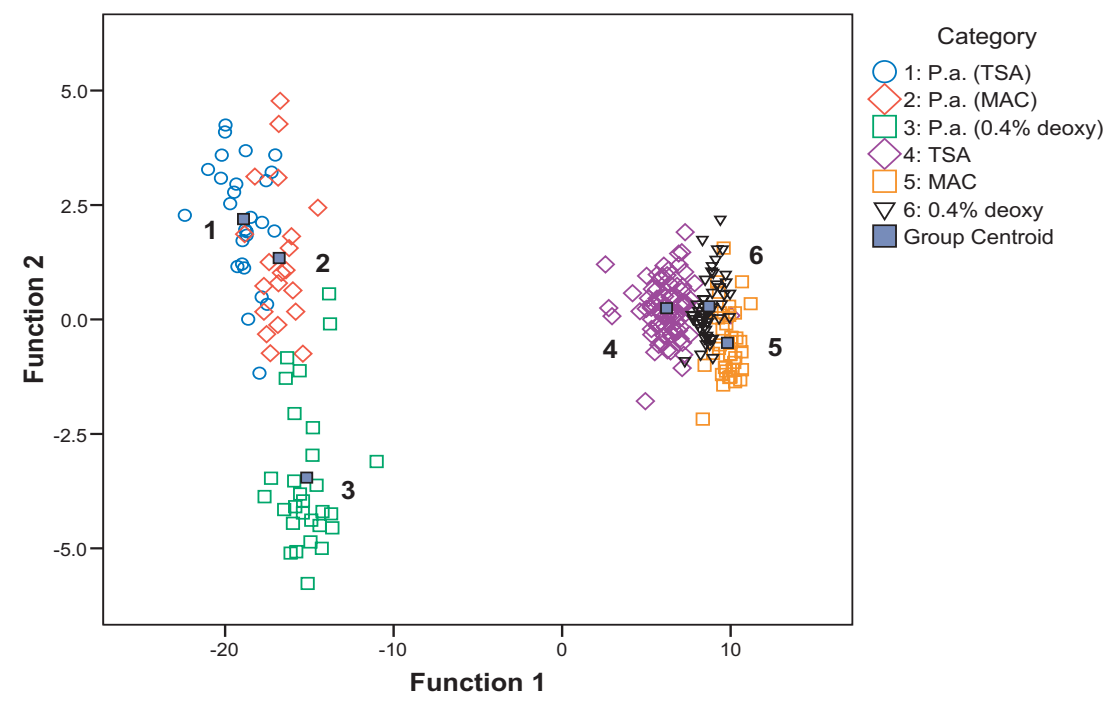

FIG. 5. (Color) DFA scores for $P$. aeruginosa cultured in three different nutrient media and ablated in argon. The bacteria cultured in the $0.4 \%$ deoxycholate medium showed the most extreme change in LIBS emission on the basis of calcium loss and are differentiated from the other two bacterial samples by DF2. The three media are also shown and are all discriminated from the bacteria by DF1 based on their similar high concentrations of sodium.

TSA and MAC, as the DF2 scores show. DF1 was again able to easily discriminate the media from the bacteria based on their high sodium concentration. The clustering of the media with one DF1 score and the bacteria with a second DF1 score again indicates that it is not possible that it is trace residual quantities of media on the bacteria caused the discrimination. The structure matrix results showed that DF2 was constructed based solely on the calcium concentration. An analysis of the total spectral power associated with the 31 emission lines in these spectra revealed that the overall emission from calcium lines decreased by $20 \% \pm 3 \%$. This does not imply that the concentration of calcium decreased by $20 \%$, but is suggestive of a decrease in the total bacterial calcium concentration. The total emission intensity of the magnesium decreased by $4 \% \pm 3 \%$, which is consistent with no significant change. The MacConkey-cultured bacteria were still distinct from the TSA-cultured samples, as was seen in air, but the largest variation between bacteria was between the deoxycholate-cultured samples and the other two. In a test performed with only the three bacteria, $79 \%$ of the total variance in the analysis was accounted for by DF1, which was the variation between the deoxycholate-cultured samples and the other two.
This alteration of $P$. aeruginosa's spectral fingerprint by a deliberately induced chemical change in the bacterial outer membrane is evidence that membrane biochemistry, the basis of serological identification, is a significant contributor to LIBS-based identification.

\section{Alteration of $E$. coli spectrum by $0.4 \%$ deoxycholate}

E. coli and P. aeruginosa are both Gram-negative bacteria and thus possess outer membranes with LPS. Therefore we expected the detergent effect of the deoxycholate to be similar (but not necessarily identical) in the two microorganisms. Samples of $E$. coli strain Nino $C$ were grown in the same three nutrient media as described in Sec. III B. A DFA was performed on the LIBS spectra obtained from these samples ablated in argon, as well as the nutrient media, as was performed on $P$. aeruginosa. The results of this analysis are shown in Fig. 6. This analysis showed marked similarities with the analysis of $P$. aeruginaosa shown in Fig. 5. Again, all three bacteria groups were easily differentiated from their growth media, which possessed highly similar spectra, by DF1. The E. coli cultured in TSA and MAC were highly similar, while the deoxycholate-cultured samples were

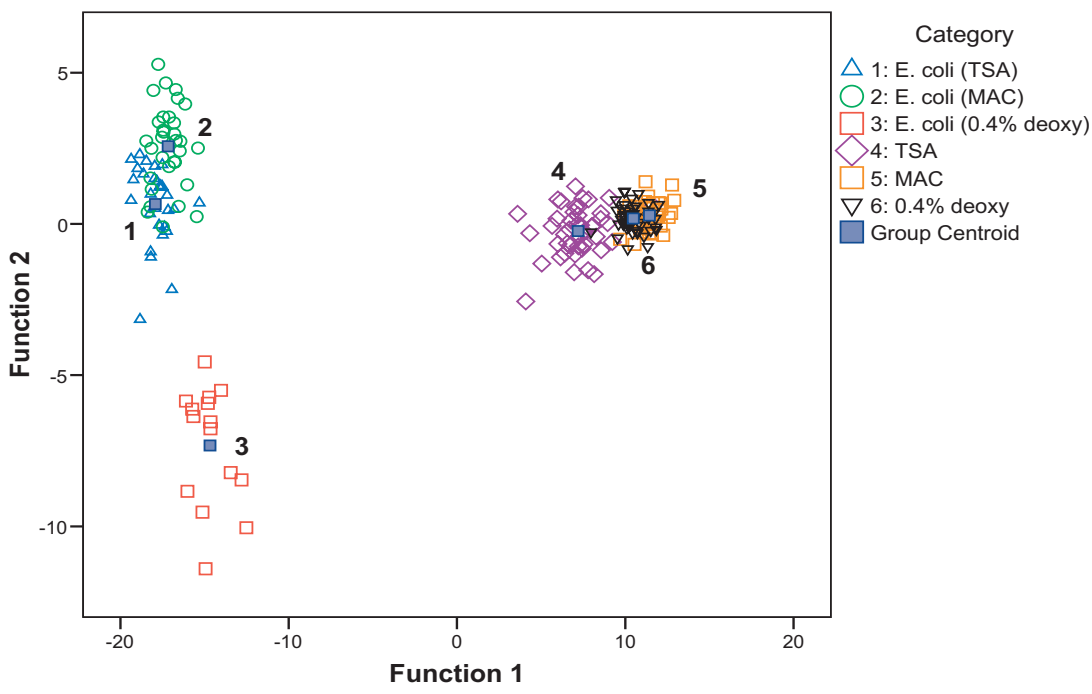

FIG. 6. (Color) DFA scores for E. coli cultured in three different nutrient media and ablated in argon. The bacteria cultured in the $0.4 \%$ deoxycholate showed the most extreme change in LIBS emission on the basis of calcium and magnesium loss and are differentiated from the other bacteria by DF2. Spectra from the three media are also shown and are all discriminated from the bacteria by DF1 based on their similar high concentrations of sodium. 

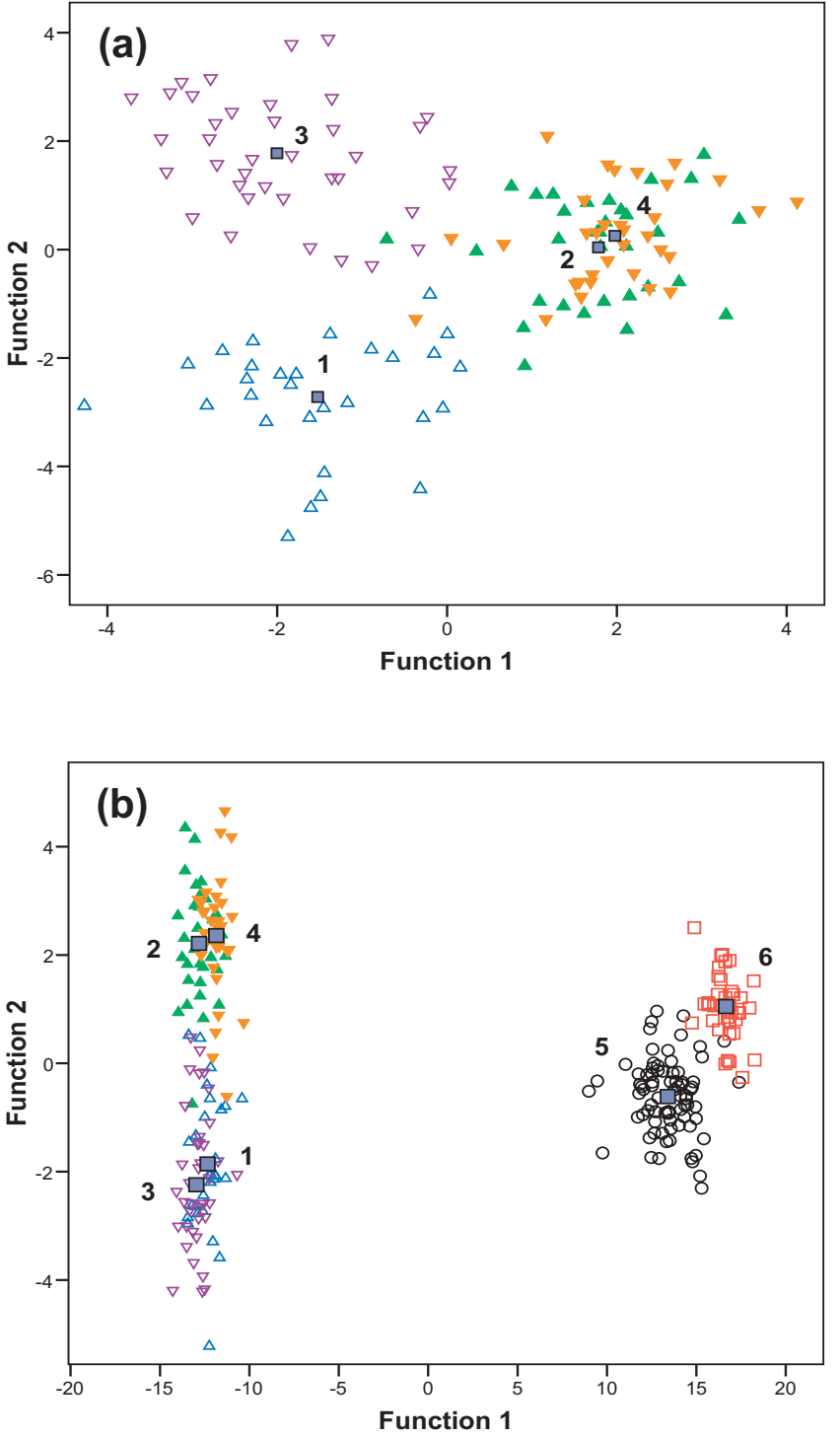

highly distinct. However, for the E. coli, these last samples were even more distinct from the other two than in the $P$. aeruginosa analysis. This is reflected by the difference between DF2 scores for the two clusters of bacteria being approximately $70 \%$ greater than it was in the $P$. aeruginosa analysis.

The cause of this larger difference was a decrease in the total emission from both calcium and also magnesium in these spectra. The total emission intensity from calcium atoms and ions decreased by $12 \% \pm 4 \%$, mirroring the alteration of the $P$. aeruginosa spectrum, but in the E. coli samples the magnesium emission intensity also decreased by a significant amount, $25 \% \pm 4 \%$.

In all cases of Gram-negative bacteria tested, reproducible differences in the LIBS emission spectra were induced by exposing the outer bacterial membrane to a known detergent agent during growth. The DFA revealed a significant difference in the spectra from these bacteria due to decreased relative emission from calcium and magnesium. We attribute this to a loss of divalent $\mathrm{Mg}$ and $\mathrm{Ca}$ cations from the outer membrane, a known effect of exposure to deoxycholate.

Category

$\triangle 1$ : Nino $C$ (TSA)

2: Nino C (MAC)

$\checkmark$ 3: HF4714 (TSA)

$\checkmark$ 4: HF4714 (MAC)

Group Centroid

Category

$\triangle 1$ : Nino C (TSA)

2: Nino C (MAC)

$\nabla$ 3: HF4714 (TSA)

4: HF4714 (MAC)

5: TSA

$\square$ 6: MAC

Group Centroid
FIG. 7. (Color) (a) DFA scores for two strains of E. coli (Nino C and HF4714) cultured in TSA (1 and 3) and MacConkey agar containing $0.01 \%$ bile salts (MAC) (2 and 4). The overlap of groups 2 and 4 indicate the two strains are no longer well differentiated on the basis of their LIBS spectra. (b) The same analysis with spectra from the two nutrient media included. The changes in the LIBS spectra induced by the bile salts caused the two MACcultured strains to appear nearly identical to each other, yet significantly different from the TSA-cultured samples, meaning the bacteria were altered in a similar way.

\section{Decrease in discrimination ability due to growth in bile salts}

We have previously reported in the ability to discriminate one strain of $E$. coli (an environmental strain known as Nino C) from a laboratory strain (a K12 derivative known as HF4714) after $24 \mathrm{~h}$ of culturing in a standard TSA medium. ${ }^{18}$ We next repeated this discrimination in argon and with samples cultured in the MacConkey agar medium with $0.01 \%$ deoxycholate (bile salts). Samples were cultured in both TSA and MAC as described previously, ablated in an argon environment, and the spectra were analyzed via a DFA. The results are shown in Fig. 7. Figure 7(a) shows the DFA scores of the four groups when analyzed together. The TSA-cultured bacteria were again well-discriminated and the cross-validated discrimination identified the strains of Nino $\mathrm{C}$ and HF4714 with $75.9 \%$ and $82.1 \%$ accuracy, respectively. The MAC-cultured bacteria, however, displayed almost no difference between the two strains with only $59.4 \%$ and $63.6 \%$ of the Nino C and HF4714 samples correctly identified in the cross-validation test. While before, spectra from Nino C and HF4714 could be correctly identified with high efficiency, this was no longer true. To test this, the MAC- 


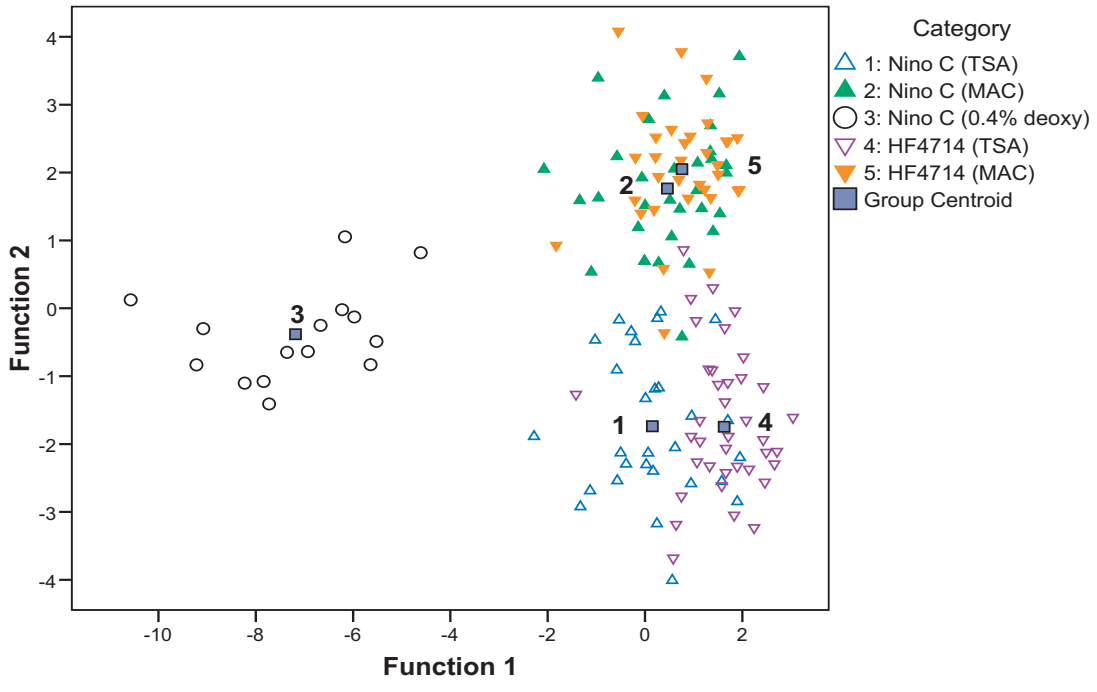

FIG. 8. (Color) DFA scores for two strains of E. coli (Nino C and HF4714) cultured in TSA (1 and 4), MacConkey agar with $0.01 \%$ bile salts (MAC) (2 and 5), and one strain cultured in TSA containing $0.4 \%$ deoxycholate (3). While all the samples cultured in TSA or MAC are similar, as evidenced by their nearly identical DF1 scores, the membrane-altered group (3) is clearly distinct. This is attributed to a true biochemical dilution of the outer membrane in the presence of high concentrations of deoxycholate and the possible formation of an extracellular polysaccharide capsule in the presence of the low concentrations of the bile salts. Strain discrimination ability has been compromised, as evidenced by the lack of grouping of HF and Nino samples. cultured Nino $\mathrm{C}$ data were removed from the analysis, and the MAC-cultured HF4714 samples were unclassified, allowing the DFA to assign the spectra to either the Nino $\mathrm{C}$ or HF4714 category. $76 \%$ of the HF4714 spectra were classified as belonging to HF4714 and 24\% were classified as belonging to the Nino $\mathrm{C}$ category. This test was repeated by eliminating all MAC-cultured HF4714 samples from the analysis and unclassifying the MAC-cultured Nino C samples, allowing the DFA to assign the spectra to either the Nino $\mathrm{C}$ or the HF4714 category. Only 47\% of the tested Nino C samples were correctly classified as Nino $\mathrm{C}$, the other $53 \%$ being incorrectly classified as HF4714 samples. The analysis could do no better than a roughly 50-50 assignment of the ungrouped cases, which is consistent with no discrimination.

We attribute the difference in the drop in discrimination efficiency between HF4714 and Nino C, as well as the relative disparity between the behaviors of the two groups, to their response to the bile salt environment. The inherent difference in the LPS composition of these two strains is most likely the cause of this. The environmental strain Nino $\mathrm{C}$ quite possibly forms a polysaccharide capsule in the presence of the low concentration of bile salts, but the HF4714, which has its $\mathrm{O}$-antigen partially missing, may show a reduced proclivity to such formation. Indeed, the severe degradation in the ability to identify Nino $\mathrm{C}$ correctly is entirely consistent with a more extreme alteration of the LIBS spectrum due to exopolysaccharide accumulation.

Figure 7(b) shows the same analysis with spectra from the two nutrient media included. It is apparent that the changes induced in the membrane by the presence of the low concentration of bile salts in the MacConkey agar were fairly consistent as the two MAC-cultured samples appeared highly similar in this analysis. Both bacteria were altered in a nearly identical fashion, and this spectral alteration removed the basis for discrimination-based on $\mathrm{Ca}$ and $\mathrm{Mg}$ content- that was demonstrated previously between the TSA-cultured bacterial samples.

Lastly, we included the previously obtained spectra from Nino C samples cultured in the $0.4 \%$ deoxycholate substrate with the TSA/MAC analysis shown in Fig. 7. The results, shown in Fig. 8, again clearly show that the detergent action of the deoxycholate on the bacteria altered the LIBS spectrum in an extreme manner, much more significantly that the low concentrations of bile salts present in the MacConkey agar were able to do. This was attributed to a true biochemical dilution of the outer membrane in the presence of high concentrations of deoxycholate and the possible formation of an extracellular biofilm at low concentrations. E. coli strain discrimination ability was lost, as evidenced by the lack of grouping of HF4714 and Nino samples.

\section{E. Genus discrimination as a function of nutrient medium}

Although the alteration of membrane biochemistry and the possible formation of a biofilm reduced the ability to use LIBS to perform strain identification, it did not eliminate the ability to differentiate between two different genera of Gramnegative bacteria, which always exhibited more significant variations between groups than different strains of the same species did.

To demonstrate this, we analyzed the LIBS spectra from two strains of E. coli (Nino C and HF4714) cultured both in TSA and MAC with $0.01 \%$ bile salts. We performed a DFA with these four data sets as well as the samples of $P$. aeruginosa cultured in both TSA and MAC. The results are shown in Fig. 9. This was a significantly more complicated analysis, and the ability to correctly classify spectra was correspondingly less accurate. However, the DFA still was able to accurately discriminate between these two bacteria as evidenced by the DF1 scores for a given type of bacteria. $P$. aeruginosa samples possessed a positive DF1 score (typically greater than about 1.2 ), while most of the E. coli samples (regardless of nutrient medium) possessed a DF1 score less than 1.2 . Only $72.4 \%$ of the E. coli Nino C cultured in TSA and $82.1 \%$ of the HF4714 cultured in TSA were correctly classified. When cultured in MAC, that accuracy decreased further to only $62.5 \%$ for the Nino C and $69.7 \%$ for the HF4714. The P. aeruginosa cultured in TSA and MAC were correctly classified only $65.4 \%$ and $57.9 \%$ of the time, respectively. However, this was only the ability to iden- 


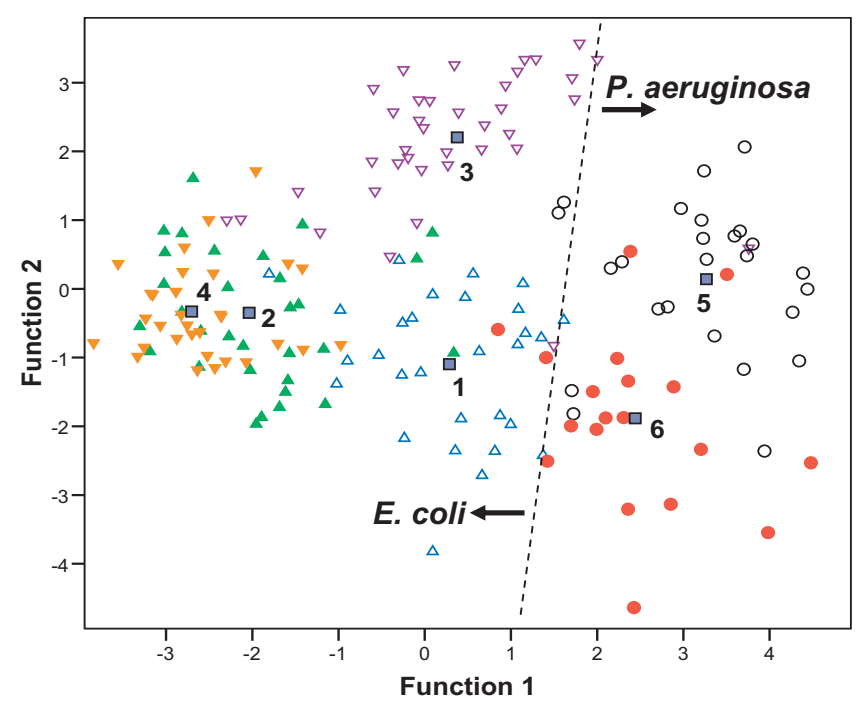

tify a particular species and strain grown on a specific nutrient medium.

A more relevant test was the ability to correctly differentiate E. coli from P. aeruginosa regardless of strain or nutrient medium. In this regard, the test was more robust. $E$. coli Nino C cultured in TSA was correctly identified as $E$. coli $86 \%$ of the time. When cultured in MAC, it was $90 \%$ of the time. E. coli HF4714 cultured in TSA was correctly identified as E. coli $95 \%$ of the time. When cultured in MAC, it was $100 \%$ of the time. P. aeruginosa cultured in TSA was correctly identified as $P$. aeruginosa $86 \%$ of the time. When cultured in MAC, it was $79 \%$ of the time. These results are summarized in Table II, where the "correct genus ID'd" column denotes the percentage of each group that was identified correctly (that is, assigned the proper E. coli or P. aeruginosa classification). The modification of the LIBS spectrum due to
Category

$\triangle 1$ : Nino $C$ (TSA)

$\triangle$ 2: Nino $C$ (MAC)

$\nabla$ 3: HF4714 (TSA)

4: HF4714 (MAC)

5: P.a. (TSA)

6: P.a. (MAC)

Group Centroid
FIG. 9. (Color) DFA scores for two strains of E. coli (Nino C and HF4714) cultured in TSA (1 and 3), MacConkey agar containing $0.01 \%$ bile salts $(2$ and 4 ), and one strain of $P$. aeruginosa cultured in TSA (5) and MacConkey agar with bile salts (6). All MacConkeycultured bacteria have filled in symbols. Bacterial discrimination by genus is accomplished by DF1 in spite of the spectral changes induced by the low concentration of bile salts in the MacConkey agar. The ability to differentiate one bacterium from another, regardless of nutrient medium, is $90.4 \%$. DF2 discriminates the two strains of E. coli cultured in the TSA medium, but the MacConkey-cultured E. coli samples have compromised strain discrimination. the low concentration of bile salts complicated the proper identification of these bacteria, but nonetheless, $90.4 \%$ of all samples were assigned to the correct group in this analysis.

The alteration of the outer membrane composition due to the deoxycholate did not inhibit the ability to correctly identify the bacterial species any more significantly than culturing in the low concentration of bile salts did. E. coli Nino C samples cultured in TSA, MAC plus $0.01 \%$ bile salts, and TSA with $0.4 \%$ deoxycholate were analyzed in a DFA with $P$. aeruginosa samples grown in the identical media. This is shown in Fig. 10. Again the bacterial samples were correctly discriminated by genus/species largely on the basis of their DF1 score, the $P$. aeruginosa possessing negative DF1 scores, and the E. coli possessing positive DF1 scores. While only $76.3 \%$ of all cases were correctly classified in this analysis, $91.4 \%$ of all cases were correctly assigned to the

TABLE II. Ability to correctly identify bacteria on the basis of its LIBS spectrum as a function of nutrient medium (TSA and MacConkey agar with $0.01 \%$ bile salts) for two strains of $E$. coli and one strain of $P$. aeruginosa. $90.4 \%$ of all bacterial samples were assigned the correct identification.

\begin{tabular}{|c|c|c|c|c|c|c|c|c|}
\hline \multirow[b]{2}{*}{ Category } & \multicolumn{6}{|c|}{$\begin{array}{l}\text { Predicted group membership } \\
(\%)\end{array}$} & \multirow[b]{2}{*}{$\begin{array}{l}\text { Correct } \\
\text { genus } \\
\text { ID'd }\end{array}$} & \multirow[b]{2}{*}{ Tota } \\
\hline & $\begin{array}{c}\text { E. coli } \\
\text { Nino C } \\
\text { (TSA) }\end{array}$ & $\begin{array}{c}E . \text { coli } \\
\text { Nino C } \\
\text { (MAC) }\end{array}$ & $\begin{array}{c}\text { E. coli } \\
\text { HF4714 } \\
\text { (TSA) }\end{array}$ & $\begin{array}{c}\text { E. coli } \\
\text { HF4714 } \\
\text { (MAC) }\end{array}$ & $\begin{array}{l}\text { P. aeruginosa } \\
\text { (TSA) }\end{array}$ & $\begin{array}{l}\text { P. aeruginosa } \\
\text { (MAC) }\end{array}$ & & \\
\hline $\begin{array}{l}\text { E. coli } \\
\text { Nino C } \\
\text { (TSA) }\end{array}$ & 72.4 & 13.8 & 0.0 & 0.0 & 0.0 & 13.8 & 86.2 & 100.0 \\
\hline $\begin{array}{l}\text { E. coli } \\
\text { Nino C } \\
\text { (MAC) }\end{array}$ & 0.0 & 62.5 & 3.1 & 25.0 & 6.3 & 3.1 & 90.6 & 100.0 \\
\hline $\begin{array}{l}\text { E. coli } \\
\text { HF4714 } \\
\text { (TSA) }\end{array}$ & 2.6 & 7.7 & 82.1 & 2.6 & 0.0 & 5.1 & 94.9 & 100.0 \\
\hline $\begin{array}{l}\text { E. coli } \\
\text { HF4714 } \\
\text { (MAC) }\end{array}$ & 3.0 & 24.2 & 3.0 & 69.7 & 0.0 & 0.0 & 100 & 100.0 \\
\hline $\begin{array}{l}\text { P. aeruginosa } \\
\text { (TSA) }\end{array}$ & 3.8 & 0.0 & 11.5 & 0.0 & 65.4 & 19.2 & 84.7 & 100.0 \\
\hline $\begin{array}{l}\text { P. aeruginosa } \\
\text { (MAC) }\end{array}$ & 5.3 & 5.3 & 10.5 & 0.0 & 21.1 & 57.9 & 78.9 & 100.0 \\
\hline
\end{tabular}




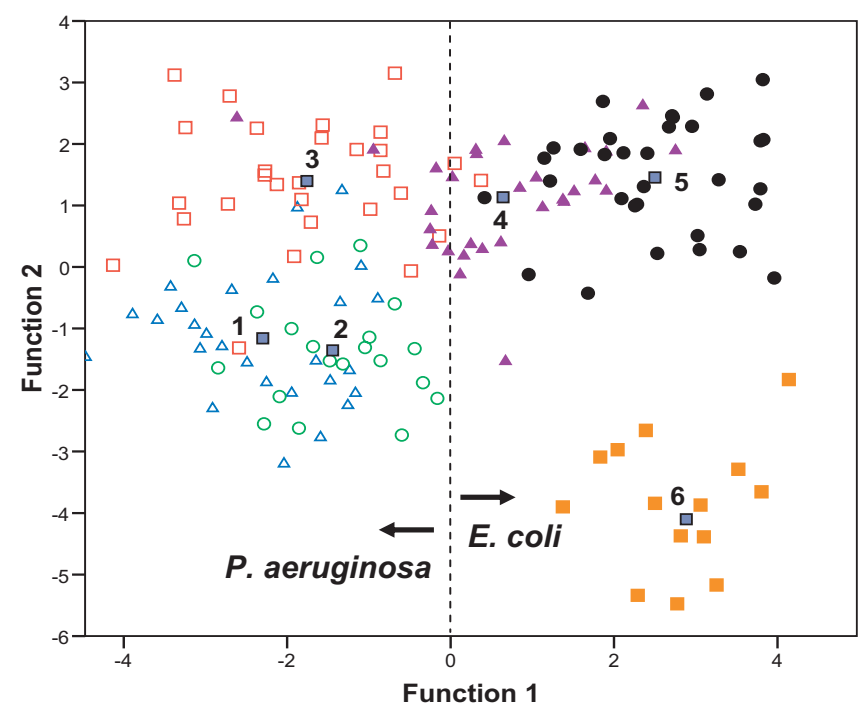

correct bacterial genus/species. This result is summarized in Table III. The two results shown in Tables II and III, although based on two types of bacteria only, are highly suggestive that the identification of one genus of bacteria relative to another is possible with the LIBS technique regardless of the environmental conditions present during the growth and life cycle of the bacteria.

\section{CONCLUSIONS}

Nanosecond single-pulse LIBs has been used to identify and discriminate between two bacterial species highly important to the clinical sciences: $E$. coli and $P$. aeruginosa. A DFA was used to analyze the LIBS spectra obtained from colonies of bacteria cultured in three different nutrient me-
Category

$\triangle$ 1: P.a. (TSA)

2: P.a. (MAC)

3: P.a. (deoxy)

4: E. coli (TSA)

5: E. coli (MAC)

6: E. coli (deoxy)

Group Centroid
FIG. 10. (Color) The first two discriminant function scores of $P$. aeruginosa samples cultured in TSA (1), MacConkey agar containing $0.01 \%$ bile salts (MAC) (2), and TSA containing $0.4 \%$ deoxycholate (3) when analyzed together with $E$. coli Nino C samples also cultured in TSA (4), MAC with bile salts (5), and TSA containing $0.4 \%$ deoxycholate (6). The ability to differentiate one bacterium from another, regardless of nutrient medium, is $91.4 \%$. DF1 performs most of the discrimination between bacterial genus in this analysis. dia: a standard TS agar, a MacConkey agar containing a $0.01 \%$ concentration of bile salts, and a TS agar with a higher $0.4 \%$ concentration of deoxycholate. For at least one of these bacteria (the Pseudomonas) growth in the presence of low concentrations of bile or bile salts may occur in a bacterial "biofilm" which is an excessive production of an exopolysaccharide capsule that acts to insulate the bacteria from its environment and acts to increase resistance to antibiotics in vivo and antibacterial agents on surfaces. ${ }^{56,57}$ The $0.4 \%$ deoxycholate concentration was chosen to exploit its known detergent action on the bacterial membrane. At these concentrations, the LPS component of the outer membrane loses integrity and the concentrations of the divalent cations that hold this membrane together can possibly change.

TABLE III. Ability to correctly identify bacteria on the basis of its LIBS spectrum as a function of nutrient medium (TSA, MacConkey agar with $0.01 \%$ bile salts, and TSA with $0.4 \%$ deoxycholate) for a single strain of $E$. coli and a single strain of $P$. aeruginosa. $91.4 \%$ of all samples were assigned the correct identification.

\begin{tabular}{|c|c|c|c|c|c|c|c|c|}
\hline \multirow[b]{2}{*}{ Category } & \multicolumn{6}{|c|}{$\begin{array}{l}\text { Predicted group membership } \\
\qquad(\%)\end{array}$} & \multirow[b]{2}{*}{$\begin{array}{l}\text { Correct } \\
\text { genus } \\
\text { ID'd }\end{array}$} & \multirow[b]{2}{*}{ Total } \\
\hline & $\begin{array}{l}\text { P. aeruginosa } \\
\text { (TSA) }\end{array}$ & $\begin{array}{l}\text { P. aeruginosa } \\
\text { (MAC) }\end{array}$ & $\begin{array}{c}\text { P. aeruginosa } \\
(0.4 \% \\
\text { deoxy })\end{array}$ & $\begin{array}{l}\text { E. coli } \\
\text { Nino C } \\
\text { (TSA) }\end{array}$ & $\begin{array}{l}\text { E. coli } \\
\text { Nino C } \\
\text { (MAC) }\end{array}$ & $\begin{array}{c}\text { E. coli } \\
\text { Nino C } \\
(0.4 \% \\
\text { deoxy })\end{array}$ & & \\
\hline $\begin{array}{l}\text { P. aeruginosa } \\
\text { (TSA) }\end{array}$ & 70.4 & 22.2 & 3.7 & 3.7 & 0.0 & 0.0 & 96.3 & 100.0 \\
\hline $\begin{array}{l}\text { P. aeruginosa } \\
\text { (MAC) }\end{array}$ & 15.0 & 65.0 & 20.0 & 0.0 & 0.0 & 0.0 & 100.0 & 100.0 \\
\hline $\begin{array}{l}\text { P. aeruginosa } \\
(0.4 \% \\
\text { deoxy })\end{array}$ & 3.4 & 3.4 & 79.3 & 13.8 & 0.0 & 0.0 & 86.2 & 100.0 \\
\hline $\begin{array}{l}\text { E. coli } \\
\text { Nino C } \\
\text { (TSA) }\end{array}$ & 0.0 & 6.9 & 6.9 & 72.4 & 10.3 & 3.4 & 86.2 & 100.0 \\
\hline $\begin{array}{l}\text { E. coli } \\
\text { Nino C } \\
\text { (MAC) }\end{array}$ & 6.3 & 0.0 & 0.0 & 3.1 & 90.6 & 0.0 & 93.8 & 100.0 \\
\hline $\begin{array}{l}\text { E. coli } \\
\text { Nino C } \\
(0.4 \% \\
\text { deoxy })\end{array}$ & 0.0 & 13.3 & 0.0 & 6.7 & 6.7 & 73.3 & 86.7 & 100.0 \\
\hline
\end{tabular}


A DFA of the LIBS spectra cultured in these various media clearly revealed reproducible changes to the spectra, confirming that LIBS can be used to probe and quantify Gram-negative outer membrane biochemistry. This is a first step toward establishing an atomic basis for the classification of bacteria, which may correlate with the epitope-based serological grouping based on $\mathrm{O}$-antigen and $\mathrm{H}$-antigen membrane chemistry.

We have demonstrated that the culturing of $P$. aeruginosa in a MacConkey agar plus bile salt medium significantly altered the LIBS spectrum when ablated in air in such a way that it no longer resembled the typical spectrum seen from these bacteria when cultured in TSA or blood agar. This was attributed to an increase in emission from calcium and a decrease in magnesium in the ablated sample possibly due to cation accumulation in a capsule around the bacteria.

The membrane basis for this change in LIBS signal was confirmed by culturing the $P$. aeruginosa in a highconcentration sodium deoxycholate TSA medium, followed by ablation in an all argon environment. The LIBS spectra from these bacteria were significantly altered from both the samples grown in a bile-free environment and the samples grown in the presence of a low concentration of bile salts. This was attributed to the disruption of the Gram-negative outer membrane by the detergent action of the deoxycholate on the LPS molecule. Decreased emission was observed from calcium, which is present in a divalent form in a region of the LPS molecule containing an eight-carbon sugar called KDO (see Fig. 1). No significant change was measured in the emission from magnesium.

This experiment was repeated with an environmental strain of $E$. coli and similar alteration of the LIBS spectrum was observed, again assigned to the disruption of the outer membrane LPS molecules. The total emission intensity from calcium atoms and ions was decreased and the magnesium emission intensity also decreased by a significant amount. This is consistent with both ions being present in the membrane in different concentrations in the two bacteria, making species discrimination possible, as was observed in our earlier works.

Loss of LIBS-based strain discrimination due to culturing in the $0.01 \%$ bile salt medium was observed when two different strains of $E$. coli were analyzed after being cultured in this medium and the TSA medium. Although efficient discrimination was possible on the unaltered bacteria, the alteration of cation concentration due to growth in the bile salt containing medium precluded any discrimination of the two strains. When compared to the spectra from bacteria cultured in a deoxycholate-rich medium $(0.4 \%)$ the low-concentration bile salt-cultured samples appeared almost identical to each other, yet were significantly different from the higherconcentration samples. We again attributed this to the loss of divalent cations from the outer membrane which is known to occur at high concentrations.

We lastly observed that in spite of serious alteration in LIBS emission due to nutrient medium-induced biochemical modification, a DFA still showed accuracy in differentiating spectra on the basis of bacterial genus and species, if not strain. The significant differences that existed between spec- tra from different genera of bacteria were not completely erased by the alteration of the membrane. This was perhaps the most significant conclusion of this work: the ability to discriminate one genus of bacteria from another with the LIBS technique persisted with better than $90 \%$ accuracy regardless of the nutrient medium in which the samples were cultured. By exposing these bacteria to an environmental stressor that could be experienced in vivo and subsequently testing them, we have demonstrated that the changes in LIBS signal observed did not inhibit the proper identification of the bacteria. Of course, a larger variety of bacteria will need to be analyzed to generalize this conclusion further. However, these early results are highly encouraging for researchers working to develop an all-optical technique to rapidly identify bacteria in clinical samples.

${ }^{1}$ D. A. Cremers and L. J. Radziemski, Handbook of Laser-Induced Breakdown Spectroscopy, 1st ed. (Wiley, Chichester, 2006).

${ }^{2}$ A. W. Miziolek, V. Palleschi, and I. Schechter, Laser Induced Breakdown Spectroscopy, 1st ed. (Cambridge University Press, Cambridge, 2006).

${ }^{3}$ E. Tognoni, V. Palleschi, M. Corsi, and G. Cristoforetti, Spectrochim. Acta, Part B 57, 1115 (2002).

${ }^{4}$ C. Pasquini, J. Cortez, L. M. C. Silva, and F. B. Gonzaga, J. Braz. Chem. Soc. 18, 463 (2007).

${ }^{5}$ For an example of the variety of applications to which LIBS has been applied, see the special edition on Laser-Induced Applied Spectroscopy, Appl. Opt. 42, 5937-6225 (2003).

${ }^{6}$ J. D. Hybl, G. A. Lithgow, and S. G. Buckley, Appl. Spectrosc. 57, 1207 (2003).

${ }^{7}$ S. Morel, M. Leone, P. Adam, and J. Amouroux, Appl. Opt. 42, 6184 (2003).

${ }^{8}$ A. C. Samuels, F. C. DeLucia, Jr., K. L. McNesby, and A. W. Miziolek, Appl. Opt. 42, 6205 (2003).

${ }^{9}$ A. Assion, M. Wollenhaupt, L. Haag, F. Mayorov, C. Sarpe-Tudoran, M. Winter, U. Kutschera, and T. Baumert, Appl. Phys. B: Lasers Opt. 77, 391 (2003).

${ }^{10}$ F. C. DeLucia, Jr., A. C. Samuels, R. S. Harmon, R. A. Walter, K. L. McNesby, A. LaPointe, R. J. Winkel, Jr., and A. W. Miziolek, IEEE Sens. J. 50, 681 (2005).

${ }^{11}$ T. Kim, Z. G. Specht, P. S. Vary, and C. T. Lin, J. Phys. Chem. B 108, 5477 (2004).

${ }^{12}$ P. B. Dixon and D. W. Hahn, Anal. Chem. 77, 631 (2005).

${ }^{13}$ J. D. Hybl, S. M. Tysk, S. R. Berry, and M. P. Jordan, Appl. Opt. 45, 8806 (2006).

${ }^{14}$ J. L. Xu, G. Mejean, W. Liu, Y. Kamali, J.-F. Daigle, A. Azarm, P. T. Simard, P. Mathieu, G. Roy, J.-R. Simard, and S. L. Chin, Appl. Phys. B: Lasers Opt. 87, 151 (2007).

${ }^{15}$ J. L. Gottfried, F. C. De Lucia, Jr, C. A. Munson, and A. W. Miziolek, Spectrochim. Acta, Part B 62, 1405 (2007).

${ }^{16}$ P. I. Tarr, Clin. Infect. Dis. 20, 1 (1995).

${ }^{17}$ J. A. Jernigan, M. A. Clemence, G. A. Stott, M. G. Titus, C. H. Alexander, C. M. Palumbo, and B. M. Farr, Infect. Control Hosp. Epidemiol. 16, 686 (1995).

${ }^{18}$ J. Diedrich, S. J. Rehse, and S. Palchaudhuri, Appl. Phys. Lett. 90, 163901 (2007).

${ }^{19}$ J. Diedrich, S. J. Rehse, and S. Palchaudhuri, J. Appl. Phys. 102, 014702 (2007).

${ }^{20}$ S. J. Rehse, J. Diedrich, and S. Palchaudhuri, Spectrochim. Acta, Part B 62, 1169 (2007).

${ }^{21}$ P. M. Griffin and R. V. Tauxe, Epidemiol. Rev. 13, 60 (1991).

${ }^{22}$ M. Baudelet, L. Guyon, J. Yu, J.-P. Wolf, T. Amodeo, E. Frejafon, and P. Laloi, Appl. Phys. Lett. 88, 063901 (2006).

${ }^{23}$ M. Baudelet, L. Guyon, J. Yu, J.-P. Wolf, T. Amodeo, E. Frejafon, and P. Laloi, J. Appl. Phys. 99, 084701 (2006).

${ }^{24}$ M. Baudelet, J. Yu, M. Bossu, J. Jovelet, J.-P. Wolf, T. Amodeo, E. Frejafon, and P. Laloi, Appl. Phys. Lett. 89, 163903 (2006).

${ }^{25}$ F. R. Blattner, G. Plunkett, C. A. Bloch, N. T. Perna, V. Burland, M. Riley, J. ColladoVides, J. D. Glasner, C. K. Rode, G. F. Mayhew, J. Gregor, N. W. Davis, H. A. Kirkpatrick, M. A. Goeden, D. J. Rose, B. Mau, and Y. Shao, Science 277, 1453 (1997). 
${ }^{26}$ N. Hoiby, High Temp. Mater. Processes (N.Y., NY, U.S.) 8, 1 (2004).

${ }^{27}$ N. Leone, G. D'Arthur, P. Adam, and J. Amouroux, High Temp. Mater Processes (N.Y., NY, U.S.) 8(1), 1 (2004).

${ }^{28}$ R. A. Harvey, P. C. Champe, and B. D. Fisher, Microbiology- Lippincott's Illustrated Reviews, 2nd ed. (Lippincott Williams \& Wilkins, Philadelphia, 2006).

${ }^{29} \mathrm{H}$. Nikaido, Bacterial Membranes and Walls, edited by L. Leive (Dekker, New York, 1973).

${ }^{30}$ H. Nikaido and T. Takae, Adv. Microb. Physiol. 20, 163 (1979).

${ }^{31}$ Y. Kamio and H. Nikaido, Biochemistry 15, 2561 (1976).

${ }^{32}$ C. R. H. Raetz, Annu. Rev. Biochem. 59, 129 (1990).

${ }^{33}$ H. Nikaido and M. Vaara, Microbiol. Rev. 49, 1 (1985).

${ }^{34}$ W. Manz, R. Amann, W. Ludwig, M. Vancanneyt, and K. H. Schleifer, Microbiology 142, 1097 (1996).

${ }^{35}$ A. W. Paton and J. C. Paton, J. Clin. Microbiol. 36, 598 (1998).

${ }^{36}$ J. G. Hacia, Nat. Genet. 21, 42 (1999).

${ }^{37}$ J. E. Ogg, M. B. Shrestha, and L. Poudayl, Infect. Immun. 19, 231 (1978).

${ }^{38}$ J. E. Ogg, B. J. Ogg, M. B. Shrestha, and L. Poudayl, Infect. Immun. 24, 974 (1979)

${ }^{39}$ L. Leive, Ann. N.Y. Acad. Sci. 235, 109 (1974).

${ }^{40}$ P. Garidel, M. Rappolt, A. B. Schromm, J. Howe, K. Lohner, J. Andra, M. H. J. Koch, and K. Brandenburg, Biochim. Biophys. Acta 1715, 122 (2005).

${ }^{41}$ S. O. Hagge, M. U. Hammer, A. Wiese, U. Seydel, and T. Gutsmann,
BMC Biochemistry 7, 15 (2006).

${ }^{42}$ M. A. Asbell and R. G. Eagon, J. Bacteriol. 92, 380 (1996).

${ }^{43}$ H. R. Ibrahim, S. Higashiguck, Y. Sugimot, and T. Aoki, J. Agric. Food Chem. 45, 89 (1997).

${ }^{44}$ S. Snyder, D. Kim, and T. J. McIntosh, Biochemistry 38, 10758 (1999).

${ }^{45}$ R. D. Lins and T. P. Straatsma, Biophys. J. 81, 1037 (2001).

${ }^{46}$ D. M. Heuman, R. S. Bajaj, and Q. Lin, J. Lipid Res. 37, 562 (1996).

${ }^{47}$ D. T. Hung and J. J. Mekalanos, Proc. Natl. Acad. Sci. U.S.A. 102, 3028 (2005).

${ }^{48}$ E. Y. Rosenberg, D. Bertenthal, M. L. Nilles, K. P. Bertrand, and H. Nikaido, Mol. Microbiol. 48, 1609 (2003).

${ }^{49}$ P. Stoodley, I. Dodds, J. D. Boyle, and H. M. Lappin-Scott, J. Appl. Microbiol. 85, 19S (1999).

${ }^{50}$ I. S. Roberts, Annu. Rev. Microbiol. 50, 285 (1996).

${ }^{51}$ J. W. Shands, Jr. and P. W. Chun, J. Biol. Chem. 255, 1221 (1980).

${ }^{52}$ Y. Iida, Spectrochim. Acta, Part B 45, 1353 (1990).

${ }^{53}$ W. Sdorra and K. Niemax, Mikrochim. Acta 107, 319 (1992).

${ }^{54}$ D. E. Kim, K. J. Yoo, H. K. Park, K. J. Oh, and D. W. Kim, Appl. Spectrosc. 51, 22 (1997)

${ }^{55}$ K. Sauer, A. K. Camper, G. D. Ehrlich, J. W. Costerton, and D. G. Davies, J. Bacteriol. 184, 1140 (2002).

${ }^{56}$ E. Drenkard and F. M. Ausubel, Nature (London) 416, 740 (2002).

${ }^{57}$ L. Hall-Stoodley, J. W. Costerton, and P. Stoodley, Nat. Rev. Microbiol. 2, 95 (2004). 